\title{
Projeto Brincar é o Melhor Remédio: Relações Pedagógi- cas Centradas nas Produções Culturais das Crianças
}

Playing is the Best Remedy Project: Pedagogical Relations Centered on the Children's Cultural Productions

\section{Resumo}

O artigo tem como objetivo discutir possibilidades pedagógicas que reconheçam e valorizem a autonomia e autoria das crianças em tratamento oncológico com os jogos e as brincadeiras ofertadas por um projeto no campo da animação cultural. Para tanto, focaliza as atividades do projeto Brincar é o Melhor Remédio, desenvolvido por meio da parceria entre o Núcleo de Aprendizagens com as Infâncias e seus Fazeres (NAIF), do Centro de Educação Física e Desportos da Universidade Federal do Espírito Santo e a Associação Capixaba Contra o Câncer Infantil (ACACCI). Trata-se de uma pesquisa-ação colaborativa, que utiliza o diário de campo e registros fotográficos como fontes. Os sujeitos da pesquisa são 30 crianças, as duas professoras e o coordenador participantes do Projeto. As análises empreendidas, em diálogo com a Sociologia da Infância e com os Estudos do Cotidiano, indicam que a entrada reativa, combinada com processos pedagógicos centrados na interação e na mediação, favoreceram a autonomia e a autoria das crianças em suas relações com as brincadeiras e jogos ofertados pelo Projeto.

Palavras-chave: Jogos. Brincadeiras. Crianças. Câncer. 
Abstract

The article aims at discussing pedagogical possibilities that acknowledge and value the autonomy and authorship of children under cancer treatment regarding games and fun activities offered by a Project in the field of cultural entertainment. To do so, it focuses the activities of the Playing is the Best Remedy Project (Projeto Brincar é o Melhor Remédio), developed through the partnership between the Learning Center with Children and their Duties (Núcleo de Aprendizagens com as Infâncias e seus Fazeres - NAIF), from the Physical Education and Sports Center, and the Capixaba Against Children's Cancer Association (Associação Capixaba Contra o Câncer Infantil - ACACCI). It is about a collaborative research-action, which uses filed diary and photographic records as sources. The research subjects are 30 children, two Teachers and the Coordinator member of the Project. The analyses undertaken, in dialogue with Children's Sociology and with Daily basis Studies, indicate that the reactive entry, combined with pedagogical processes centered on interaction and mediation, they favor the children's autonomy and authorship regarding their relations with the fun activities and games offered by the Project.

Keywords: Games. Fun activities. Children. Cancer. 


\section{INTRODUÇÃO}

Estima-se que no Brasil, no biênio 2018-2019, ocorrerão 12.500 novos casos de câncer infanto-juvenil. As Regiões Sudeste e Nordeste apresentarão, respectivamente, 5.300 e 2.900 novos casos, seguidas pelas regiões Centro-Oeste, com 1.800 casos, Região Sul, com 1.300 casos, e Região Norte, com 1.200 casos (INSTITUTO NACIONAL DE CÂNCER - INCA, 2019) Dentre esses novos casos, 80\% das crianças e adolescentes acometidos pela doença poderão ser curados se diagnosticados precocemente e tratados em centros especializados. A sobrevida de pacientes infanto-juvenis varia de acordo com a região do país. Os índices mais elevados estão concentrados nas regiões Sul (75\%) e Sudeste (70\%), do que no Centro-Oeste (65\%), Nordeste (60\%) e Norte (50\%) (INCA, 2019).

O tratamento oncológico tem assumido, cada vez mais, um caráter interdisciplinar, em que diferentes áreas e profissionais interagem para dar suporte físico, psicológico e emocional para as crianças e seus familiares. Em Vitória/ES, a Associação Capixaba Contra o Câncer Infantil (ACACCI), fundada em 15 de março de 1988, é uma instituição não governamental, sem fins lucrativos, que atende, anualmente, cerca de 300 crianças que estão em tratamento oncológico. São pacientes provenientes do interior do estado do Espírito Santo e dos municípios limítrofes da Bahia e Minas Gerais, além de crianças do próprio município de Vitória que não possuem recursos financeiros para se manterem na capital capixaba durante o tratamento. As crianças provenientes da capital capixaba não ficam hospedadas na instituição, mas recebem acompanhamento nutricional, fisioterapêutico, assistência social, classe hospitalar, além de atividades culturais e recreativas. A ACACCI hospeda, simultaneamente, 30 crianças e seus responsáveis.

O apoio da ACACCI tem contribuído para maior adesão ao tratamento, que é longo e dispendioso. Nessa instituição, crianças e familiares recebem acompanhamento nutricional, fisioterapêutico, assistência social e classe hospitalar, além de atividades no campo da animação cultural, mediadas pelo projeto Brincar é o Melhor Remédio. A animação cultural é uma proposta de pedagogia social que não se restringe a um campo único de intervenção. Pode ser desenvolvida no âmbito do lazer, da escola, dos sindicatos, da família, enfim, em qualquer espaço possível de educação. Trata-se de uma intervenção pedagógica, pautada na ideia de mediação, que pretende servir de estímulo às organizações comunitárias, ao provocar questionamentos acerca da ordem social estabelecida, contribuindo para a construção de uma sociedade mais justa.

O projeto Brincar é o Melhor Remédio, registrado no Sistema de Informação de Extensão da Universidade Federal do Espírito Santo (SIEX/UFES n 401559) é desenvolvido, desde março de 2017, por meio da parceria firmada entre o Núcleo de Aprendizagens com as Infâncias e seus Fazeres (NAIF) do Centro de Educação Física e Desportos (CEFD) da Universidade Federal do Espírito Santo (UFES) e a ACACCI e tem como objetivo principal proporcionar a vivência de atividades lúdicas, por meio de jogos e brincadeiras para as crianças que são acolhidas pela referida instituição durante o tratamento oncológico, fomentando, nesse processo, a formação docente e a produção de conhecimentos pedagógicos para atuação nesse campo. 
A dimensão lúdica é uma importante aliada das crianças no enfrentamento da enfermidade, contribuindo para que elas tirem o foco da doença e ressignifiquem as suas realidades, potencializando os seus momentos de alegria, de fantasia e de esperança. A prática de jogos e brincadeiras auxilia no processo de desospitalização das crianças, oportunizando espaços e tempos para que elas vivenciem as suas infâncias, apesar das limitações impostas pela enfermidade e pelo tratamento, principalmente no diz respeito à baixa imunidade, indisposição e fadiga. A desospitalização se constitui como uma alternativa às práticas hospitalares. É uma maneira de humanizar a recuperação do paciente, otimizando o seu atendimento por meio da socialização em um ambiente de assistência, com trocas e interações sociais com seus pares (GAZETA, 1998). Para Azevêdo (2011, p. 565-566), o brincar contribui “[...] amenizando as repercussões do adoecimento na esfera psíquica e física, e atenuando os impactos negativos provenientes da ruptura do contexto sociofamiliar e dos procedimentos utilizados no tratamento".

Contudo, as atividades lúdicas são marcadas pela dimensão subjetiva, ou seja, pelos sentidos que os indivíduos atribuem a elas. Para Certeau (1994), os indivíduos não consomem passivamente os bens culturais que lhes são ofertados, pois há uma estética da recepção, em que os sujeitos imprimem as suas marcas singulares nesses artefatos culturais. Portanto, valorizar essas práticas de apropriação que as crianças têm sobre as suas atividades lúdicas é pressuposto fundamental para oferecer um projeto em consonância com as suas expectativas e possibilidades. No caso específico de crianças em tratamento oncológico, essa valorização contribui para que a criança tenha restituída um pouco de sua autonomia e controle sobre a sua própria vida, aspectos altamente afetados durante o tratamento. Para Mello, Zandominegue, Barbosa, Martins, \& Santos (2016),

Ao brincar e jogar, as crianças vão se construindo como sujeitos de sua experiência social, organizando com autonomia suas ações e interações, criando regras de convivência social e de participação nas atividades brincantes. Nesse processo, elas instituem coletivamente uma ordem social que rege as relações entre pares e se afirmam como autoras de suas práticas sociais e culturais (p. 144).

Concebemos as crianças, mesmo aquelas enfermas, como autoras de suas próprias vidas e sujeitos sociais competentes, que recebem e transformam os produtos culturais apresentados. Essa perspectiva busca superar a concepção de criança como um "vir a ser" ou como "um ser em devir", que precisa ser preenchido pela racionalidade do adulto para se tornar um ser ontologicamente pleno (Sarmento, 2013). Nesse sentido, valorizamos as produções culturais das crianças, as suas inventividades e autorias nas relações que estabelecem com os jogos e brincadeiras mediadas pelo projeto Brincar é o Melhor Remédio.

No campo da Educação Física escolar, sobretudo na Educação Infantil (Barbosa, Martins, \& Mello, 2017; Mello, Ferreira Neto, \& Votre, 2009; Mello, Zandominegue, Vieira, Silva, Assis, Barbosa, \& Martins, 2016), no contexto dos projetos sociais (Mello, 
Silva, Jorge, Schneider, \& Santos, 2018) e nos trabalhos realizados com pessoas com deficiência intelectual (Mello, Santos, Rodrigues, \& Santos, 2014), as pesquisas do NAIF têm valorizado o protagonismo das crianças, as suas produções culturais e autorias nos processos de ensino-aprendizagem mediados pela Educação Física.

Nas ações destinadas às crianças em tratamento oncológico, constatamos a incipiência de abordagens que reconheçam e valorizem a autonomia e as autorias dos infantis. Nos trabalhos encontrados, especialmente no campo da Educação Física, ainda prevalece um olhar que enxerga a criança em tratamento oncológico na perspectiva da enfermidade, tratando-a apenas como paciente. Na busca por referenciais teórico-metodológicos que tratam da temática em questão nos principais periódicos científicos da Educação Física brasileira (Revista Brasileira de Ciências do Esporte, Movimento, Motrivivência, Pensar a Prática, Revista de Educação Física da UEM, Motriz e Revista Brasileira de Educação Física e Esportes), constatamos a incipiência de produções sobre o assunto, sinalizando que há um vasto campo de possibilidades que precisa ser explorado, especialmente, o que contempla situações concretas de ensino-aprendizagem. Buscamos artigos que associam a Educação Física às crianças em tratamento oncológico. Encontramos vários textos que relacionam atividade física e câncer, no viés do exercício físico, mas poucos que abordam as contribuições dos jogos e das brincadeiras no enfrentamento da enfermidade.

Buscando romper com essa visão, o artigo tem como objetivo discutir, por meio das experiências vivenciadas no projeto Brincar é o Melhor Remédio, possibilidades para que Educação Física estabeleça relações pedagógicas que reconheçam e valorizem a autonomia e a autoria das crianças em tratamento oncológico com os jogos e as brincadeiras ofertadas pelo Projeto.

\section{MÉTODO}

O projeto Brincar é o Melhor Remédio está situado no âmbito da animação cultural e busca articular a mediação pedagógica com a formação de professores e a produção de conhecimentos. Por meio de experiências brincantes, construídas com as crianças acolhidas pela ACACCI, são fomentados conhecimentos para a mediação pedagógica da Educação Física nesse contexto.

Para materializar essa perspectiva pedagógica, o projeto adota a Pesquisa-Ação Colaborativa (Ibiapina, 2008) como orientação metodológica. Esse método busca conciliar formação de professores e a produção de conhecimentos, com base nas experiências pedagógicas desenvolvidas e nas interações entre os diferentes sujeitos envolvidos nesse processo. Nesse método, destaca-se a valorização de atitudes de colaboração e reflexão crítica entre os sujeitos, "[...] calcados em decisões e análises construídas por meio de negociações coletivas, tornam-se coparceiros, cousuários e coautores de processos investigativos delineados a partir da participação ativa, consciente e deliberada" (Ibiapina, 2008, p. 26).

A vivência de jogos e brincadeiras no projeto tem uma periodicidade semanal, com mediações realizadas às quintas-feiras, das 14 às 17 horas. 0 público-alvo 
é composto por crianças, de 4 a 12 anos de idade, que estão em tratamento oncológico e que são acolhidas pela ACACCl. As mediações são realizadas em diferentes espaços da instituição, sobretudo, na brinquedoteca e no pátio externo. O projeto é conduzido por duas professoras de Educação Física, uma em formação inicial e outra em formação continuada, mestranda do PPGEF/UFES, e o coordenador do Projeto, professor do CEFD/UFES. O projeto Brincar é o Melhor Remédio busca permanente diálogo entre as áreas do conhecimento (Educação Física, Serviço Social, Fisioterapia, Pedagogia) e sujeitos presentes no cotidiano da ACACCl, promovendo, assim, uma abordagem interdisciplinar em suas ações.

Diferentes jogos e brincadeiras são mobilizados no processo de mediação pedagógica, considerando as possibilidades, as necessidades e os interesses das crianças. As mediações pedagógicas ocorrem por meio de brincadeiras historiadas, com predomínio das situações de faz de conta, por meio de brinquedos e brincadeiras populares, com ou sem materiais estruturados, por meio de brinquedos cantados, parlendas, construção de brinquedos, brincadeiras com os esportes, dentre outras manifestações da cultura lúdica. As atividades são desenvolvidas sempre com base nos diálogos e nas interações com as crianças, acolhendo as suas vozes, representações e sentidos construídos nas relações com os jogos, com as brincadeiras e com os outros sujeitos envolvidos.

Os dados deste artigo foram produzidos nas relações pedagógicas ocorridas no projeto Brincar é o Melhor Remédio e sistematizados em diário de campo e em registros fotográficos. São sujeitos deste estudo 30 crianças, as duas professoras e o coordenador participantes do Projeto. Utilizamos nomes fictícios, para manter a identidade dos participantes da pesquisa no anonimato. 0 projeto foi submetido e aprovado pelo Comitê de Ética em Pesquisas com Seres Humanos da UFES (Parecer $n^{\circ}$ 2.650.946). Utilizamos a Análise de Conteúdo (AC), proposta por Bardin (2011), para lidar com os dados produzidos. A AC incide sobre a mensagem escrita, oral, gestual, silenciosa, figurativa e documental. Nesta pesquisa, focalizamos as mensagens escritas, que foram sistematizadas em diário de campo e, nesse processo, percorremos os três polos cronológicos propostos pela autora (pré-análise; exploração do material; inferência e interpretação) a fim de compreendermos as mensagens trabalhadas. Na etapa de inferência e interpretação, articulamos os dados produzidos com os pressupostos da Sociologia da Infância, sobretudo com os estudos de Manuel Jacinto Sarmento e Willian Corsaro, e com os Estudos do Cotidiano, de Michel de Certeau, campos do conhecimento e autores que permitiram dar visibilidade e reconhecer o protagonismo das crianças nesse processo pedagógico.

\section{RESULTADOS}

Discutiremos três encaminhamentos pedagógicos adotados pelo projeto Brincar é o Melhor Remédio que buscaram reconhecer e dar visibilidade aos anseios, necessidades e possibilidades das crianças participantes do projeto, valorizando 
as suas autorias nas relações que estabelecemos com elas. Esses encaminhamentos são entrada reativa, interações e mediações. Eles não estavam previstos a priori, mas foram assumidos durante o desenvolvimento do Projeto, ratificando a ideia de que os conhecimentos pedagógicos não antecedem à ação, mas nela são constituídos (Tardiff, 2002). Neste tópico, utilizaremos a narrativa na terceira pessoa do plural, pois as análises incidem sobre as nossas próprias práticas pedagógicas, por meio espiral proposto pela Pesquisa-Ação Colaborativa: ação, observação, reflexão e nova ação (Ibiapina, 2008).

No início do Projeto, como não tínhamos experiências sobre o modo de intervir com crianças em tratamento oncológico, operamos com uma lógica próxima da Educação Física escolar. Nesse sentido, planejamos aulas centradas em jogos e brincadeiras que julgávamos viáveis ao público-alvo, ofertando atividades lúdicas com baixas demandas energéticas. Tínhamos muito receio que as crianças se machucassem, por isso o cuidado excessivo foi a tônica em nossos primeiros contatos com elas. Estávamos impregnados pela visão médico-hospitalar, que enxerga a criança em tratamento apenas como paciente.

Dessa forma, não obtivemos êxito em nossas primeiras ações pedagógicas. As crianças não foram receptivas às nossas propostas, elas nos olhavam com desconfiança e não aderiram aos jogos e as brincadeiras que propúnhamos. Além disso, por estarmos autocentrados em nossos planejamentos, não fomos sensíveis em perceber o que se passava com elas, se estavam tristes, introspectivas ou indispostas para brincar e/ou se relacionar com os outros. Isso gerou uma grande frustação em nós, mas, por outro lado, foi a "mola propulsora" em nossas reflexões para que procurássemos, no diálogo com a Sociologia da Infância, meios para interagirmos com as crianças participantes do Projeto. Nesse sentido, a ideia de entrada reativa, proposta por Willian Corsaro (2011), foi fundamental para que estabelecêssemos relações de confiança e respeito com as crianças.

Corsaro (2011) afirma que o contato estabelecido com a criança e como ela aceita a presença do adulto é determinante nas interações que serão estabelecidas entre esses sujeitos. Para que ocorra uma interação positiva, a criança deve permitir a aproximação do adulto. Entretanto, inúmeras questões inviabilizam interações baseadas no respeito e na confiança, dentre as quais, destacamos: a) relações assimétricas de poder, em que os adultos tendem a se aproximar das crianças de forma impositiva e controladora; b) o predomínio de uma concepção de infância que considera as crianças como seres incompletos e incompetentes para pensarem e agirem sobre si mesmos. A criança é enxergada como um "vir a ser", que, devido aos seus déficits, precisa ser preenchida pelo adulto para que se torne um ser ontologicamente pleno; e c) falta de sensibilidade para perceber as produções culturais das crianças, que, mesmo subjugadas pelos adultos, se manifestam constantemente nas instituições que as acolhem. Para Finco e Oliveira (2011): 
Apesar de toda bagagem de estereótipos, as crianças pequenas ainda encontram espaços para a transgressão, para a superação e para expressão dos seus desejos. Assim, as crianças pequenas, com seus corpos e com suas espontaneidades, problematizam e questionam esses modelos centrados no adulto (p. 72).

A fim de superar essas relações adultocêntricas (Sarmento, 2013) e de nos aproximarmos de maneira positiva das crianças, assumimos a entrada reativa como postura pedagógica. Chegamos de maneira menos expansiva e esperamos que as crianças reagissem a nossa presença, fomos aos espaços que elas comumente frequentam na $\mathrm{ACACCl}$, como a brinquedoteca e a sala de jogos. Adotamos o comportamento do adulto atípico, que busca se relacionar com as crianças respeitando-as, sem impor a autoridade que os demais adultos da instituição lhes impõem. O excerto abaixo, extraído do Diário de Campo, ilustra a postura adotada e como uma criança reagiu a ela:

Nesse dia, fomos para a sala de jogos e começamos a brincar na mesa de totó. A cada gol que fazíamos, comemorávamos com entusiasmo. Sofia, que estava próxima, brincando sozinha no Xbox [jogo eletrônico] despertou interesse em nosso jogo e se aproximou. Convidamos ela para jogar, que, mesmo ressabiada, aceitou dizendo: "só vou brincar um pouquinho, enquanto meu jogo está no pause” (DIÁRIO DE CAMPO, 2-3-2017).

De maneira gradativa e não linear, fomos conquistando a confiança das crianças e o acesso a elas. Cabe ressaltar que a entrada reativa não ocorreu somente no início das atividades do Projeto, essa postura perdura até os dias atuais. As crianças acolhidas pela $\mathrm{ACACCI}$, em função da enfermidade e das asperezas do tratamento, apresentam uma grande instabilidade emocional. Por isso, é preciso ter sensibilidade às condições físicas, psíquicas e emocionais das crianças a cada encontro, dando espaço para que elas manifestem as suas motivações e interesses pelas atividades lúdicas. A entrada reativa foi, e ainda é, determinante para estabelecer as relações pedagógicas no projeto Brincar é o Melhor Remédio, que ocorrem em duas dimensões: interações e mediações.

Nas interações, buscamos nos relacionar com as crianças a partir das brincadeiras que elas estão vivenciando. Quando chegamos na ACACCI, por volta das 14 horas, já encontramos parte das crianças na brinquedoteca, geralmente brincando sozinhas. Aproximamo-nos delas e verificamos, por meio da entrada reativa, a sua receptividade e o grau de abertura para participarem de novas brincadeiras. Quando percebemos que elas não estão dispostas a brincar em grupo, interagimos por meio das brincadeiras que já estavam vivenciando. Nas interações, constatamos a importância das brincadeiras no processo de ressignificação das realidades que as crianças estão vivendo, como demonstra o seguinte relato:

A brincadeira de médico foi uma constante nas interações que estabelecemos com as crianças. Hoje brinquei de médica com Beatriz, que definiu os papeis da brincadeira: eu fui a médica e ela a mãe de uma criança doente. 
Quando chegou ao hospital, a mãe relatou os sintomas da filha (boneca) e aconselhou à médica que pedisse alguns exames de sangue. Depois que retornou à médica com os exames, a mãe disse para a "doutora" receitar um antibiótico, procedimento que foi prontamente encaminhado (DIÁRIO DE CAMPO, 20-4-2017).

Pelo relato fica clara a relação da brincadeira com a situação que a criança está vivenciando. Os elementos presentes em seu cotidiano se manifestaram na atividade lúdica: médica, exame de sangue, hospital, antibiótico, sintomas. A brincadeira é um meio para a criança enunciar os seus medos e angústias, deslocando-se "[...] de uma posição passiva, a condição de paciente, para uma mais ativa, passando à ação e desenvolvendo as suas potencialidades" (Vieira \& Lima, 2008, p. 375). Ao inverter os papeis sociais na brincadeira, a criança estabelece um processo de reprodução interpretativa (Corsaro, 2011). Para o referido autor, os infantis não se apropriam e reproduzem de maneira mecânica nas suas atividades lúdicas os aspectos dos contextos em que estão inseridas, mas operam sobre eles, imprimindo as suas marcas autorais, afirmando-se, assim, como protagonistas de suas ações.

Durante a brincadeira, a criança assume o controle da situação, exercendo a sua autonomia e autoria sobre as atividades lúdicas. No cotidiano da criança que está enferma, esses dois aspectos são extremamente afetados, subjugando-a às contingências impostas pelo tratamento. Elas perdem o controle sobre as suas próprias vidas, restando-lhes um papel passivo diante das circunstâncias. Ao ressignificar determinada situação, a brincadeira contribui para a criança superar medos e inseguranças, melhorando a sua autoestima e o seu suporte emocional no enfretamento da enfermidade e do tratamento. Sarmento (2002) ressalta a importância das brincadeiras para as crianças no enfrentamento das adversidades, um meio pelo qual elas podem reconstruir realidades tão duras e avassaladoras:

[...] o que relatos e estudos das crianças da guerra nos contam é essa forma de conseguir criar um mundo outro, nas condições da mais dura adversidade, através do jogo e da ficção de uma existência onde até o horror aparece transmudado em projeção imaginária de uma realidade alternativa. Pedro Rosa Mendes conta no livro 'a Baía dos Tigres' que viu uma criança entre as ruínas da cidade do Bié, em Angola, jogando futebol, indiferente à desolação à sua volta. O esférico com que se entretinha - imaginando-se o Eusébio ou o Pelé da época, como qualquer criança de qualquer outra parte do mundo - era, à falta de melhor, os restos de uma caveira humana: 'não é por maldade. O crânio estava disponivel, perto e seco. Tu e eu conhecemos as balizas da humanidade: crânios enterram-se, bolas são redondas (p. 2).

Além das brincadeiras de médico, as brincadeiras de super-heróis também foram recorrentes nas interações que estabelecemos com as crianças no Projeto. Por meio das atividades lúdicas com os super-heróis, as crianças assumem superpoderes que as habilitam, no plano simbólico, a realizarem os seus desejos. Para 
Brougère (2008), as brincadeiras com super-heróis recebem influência dos desenhos animados, que são ressignificados pelas crianças. No momento da brincadeira as limitações impostas pela enfermidade cedem lugar para a realização de sonhos e fantasias. De acordo com Redin (2009), as crianças "[...] gostam dos desafios que elas próprias criam, e o prazer está em poder modificar e criar novas regras e conduzir a brincadeira ao seu modo" (p. 120). Essa característica que as crianças imprimem às atividades lúdicas se evidencia no seguinte relato:

Durante o desenvolvimento de uma brincadeira, o Super-Homem, personagem assumido pela criança, decide que seria o palhaço e vai até a "arara de fantasias" da brinquedoteca, escolhe uma fantasia de palhaço, pega uma peruca para ele, outra para a professora do Projeto e mais uma para a responsável da brinquedoteca, fantasiando todas de palhaço (DIÁRIO DE CAMPO, 17-8-2017).

As mediações também caracterizaram as relações pedagógicas estabelecidas pelo projeto Brincar é o Melhor Remédio. Diferentemente das interações, nas mediações, quando percebemos abertura e acolhimento das crianças, fomos mais propositivos em relação as brincadeiras e aos jogos vivenciados no Projeto. Entretanto, mesmo sendo propositivos, continuamos atentos às práticas de apropriação que as crianças imprimiram nos bens culturais que ofertamos. Ancorados em Certeau (1994), compreendemos que os praticantes do cotidiano não absorvem passivamente os produtos culturais, como jogos, brinquedos e brincadeiras, que lhes são apresentados. Há um consumo produtivo, uma estética da recepção, que denota diferentes formas de apropriação cultural. Reconhecer e valorizar essas produções é uma forma de considerar o protagonismo e a autoria das crianças em suas relações com os jogos e a brincadeiras mediados pelo Projeto.

Nos seguintes relatos e na Foto 1, extraídos de um contexto em que as crianças estavam construindo um berimbau de brinquedo, é possível perceber diferentes práticas de apropriação por parte das crianças e a escuta sensível das professoras:

Quando a mestranda apresenta para as crianças a construção de um berimbau de brinquedo, montado com materiais alternativos, Edgard pega um lápis de colorir põe no "arame" do berimbau e diz: "olha tia, é um arco e flecha". As professoras do Projeto acham interessante a ideia e compartilham com as outras crianças (DIÁRIO DE CAMPO, 5-4-2018).

Durante o processo da confecção do berimbau de brinquedo, Larissa pega uma verga e começa a colocar vários pedaços de fita crepe, prendendo-a no chão. Essa criança se dirige para mestranda e diz: "tia isso aqui é para ele não se mexer na hora de tirar sangue, ele está se mexendo muito, não pode". Diante desse novo significado dado a brincadeira, a mestranda pergunta: "e você, se mexe muito para tirar sangue?" e a Larissa responde: "não tia, eu fico quietinha" (DIÁRIO DE CAMPO, 5-4-2018). 


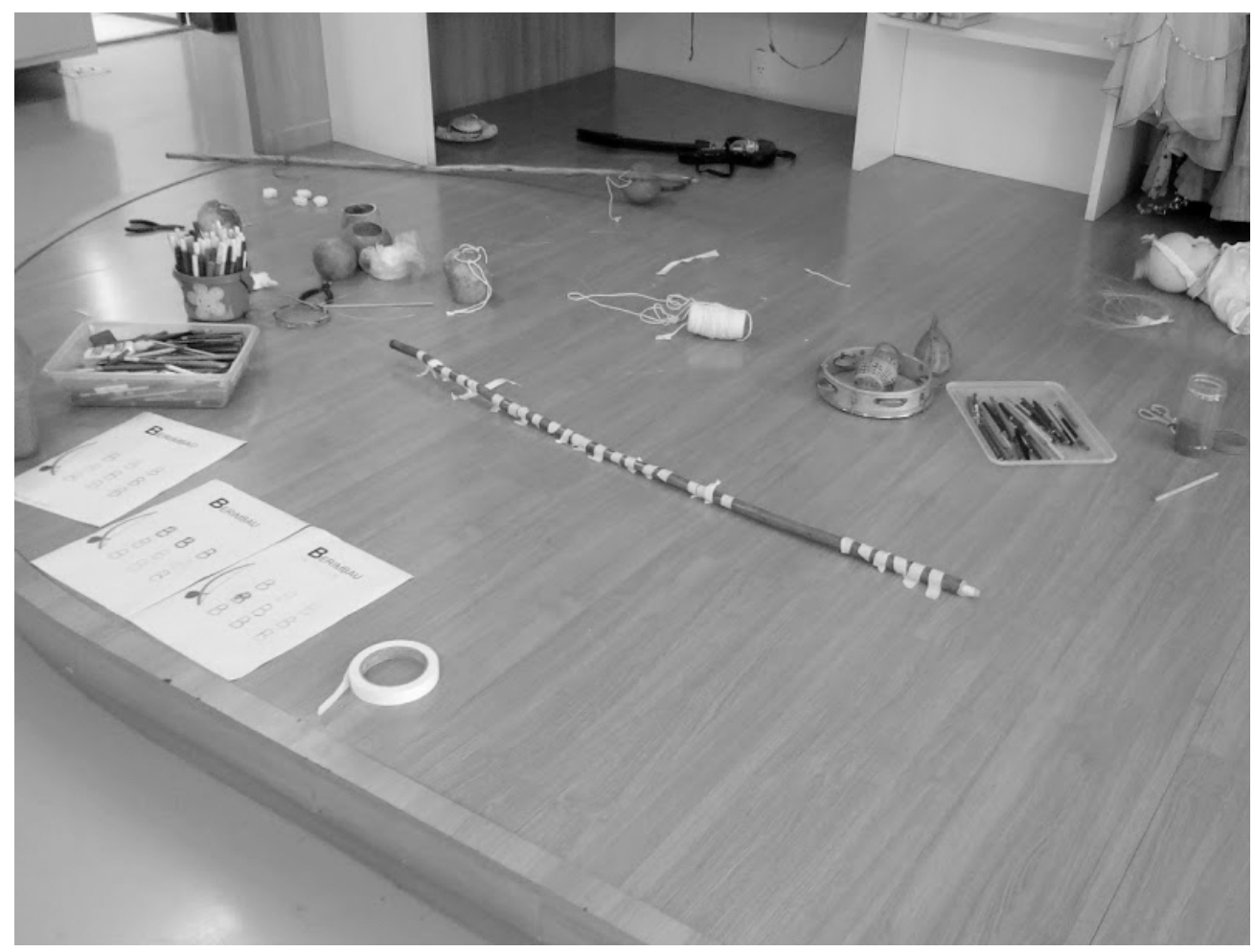

Figura 1: Construção do berimbau de brinquedo.

Inicialmente, em nossas medições, escolhíamos os jogos e as brincadeiras de maneira aleatória. Elegíamos as atividades que, em nossa opinião, seriam atraentes para as crianças. De fato, essa estratégia teve êxito durante um certo tempo, contudo, chegou um momento em que ela se esgotou e sentimos necessidade de estabelecer algo mais duradouro, que desse uma certa continuidade de um encontro para o outro. Ao refletirmos sobre as nossas próprias práticas, chegamos à conclusão de que a oferta de atividades isoladas dificultava a compreensão, por parte das crianças e nossa também, de um trabalho permanente e sistematizado. Embora as nossas relações pedagógicas variem muito, em termos de frequência e quantidade de crianças presentes em cada dia, julgamos necessário estabelecer conexões entre os encontros, potencializando, dessa forma, a construção coletiva de sentidos para as atividades propostas.

Em conversa com as crianças, escolhemos algumas temáticas que orientariam as nossas mediações. No processo de escolha, consideramos os interesses das crianças, o contexto social vivenciado (época da Copa do Mundo) e as possibilidades que as temáticas ofereciam para uma ampla oferta de jogos e brincadeiras a elas relacionados. Com base nesses critérios, definimos as seguintes temáticas: Brincando com a Copa do Mundo; Brincando com a Cultura Popular; e Brincando com os Esportes. Embora cada temática tivesse a sua especificidade, todas elas tiveram um ponto em comum: a construção de brinquedos. As Fotos 2, 3, 4 e 5 demonstram alguns brinquedos construídos pelas crianças no Projeto: 
Figura 2: Brincando com a Copa do Mundo.

Figura 3: Brincando com a Copa do Mundo.

Figura 4: Brincando com a Cultura Popular.
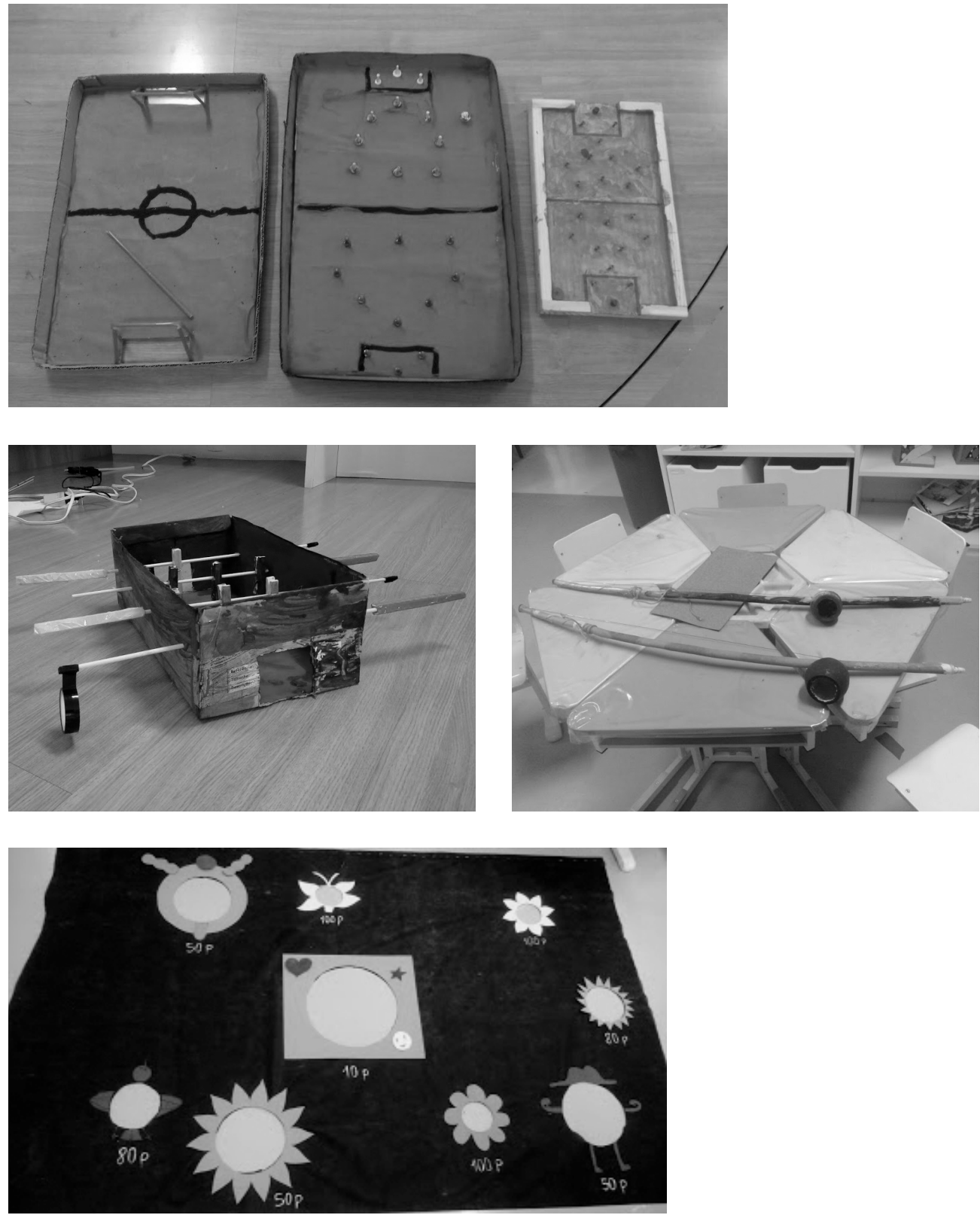

No contexto do Projeto, a construção de brinquedos foi um importante meio para promoção da autonomia e para projeção da identidade pessoal das crianças nos artefatos produzidos. Apesar de propormos a elaboração de um determinado brinquedo associado à temática trabalhada, no processo de construção as crianças foram imprimindo as suas marcas pessoais, gerando, no final de cada ação, distintas produções culturais. Tão importante quanto brincar com os objetos produzidos, é o processo de construção de brinquedos, que permite a criança exercer o seu protagonismo e as suas capacidades criativas de maneira autodeterminada. Os brinquedos 
foram construídos com materiais recicláveis, como garrafas PET, caixas de sapato, pedaços de madeiras, arames de pneus, dentre outros. Certeau (1994) afirma que a produção por meio de sucatas torna o sujeito autor de suas práticas sociais, ao deslocar a atenção do consumo supostamente passivo dos produtos recebidos para a criação anônima nascida da prática do desvio no uso desses produtos. Diferentemente dos brinquedos artesanais, em que a ação humana exprime identidade própria em sua construção, "O brinquedo industrializado, apesar do alto custo, de ser atraente, nem sempre oferece à criança a possibilidade de interação, de criação, de participação, resta-lhe apenas ser espectadora” (Melo, 2004, p. 180).

As relações pedagógicas observadas e sistematizadas a partir das produções culturais infantis mostraram que ao compartilhar suas experiências brincantes, seja por meio de elementos presentes do seu cotidiano, de construção de brinquedos e de fantasias surgidas com personagens de super-heróis, as crianças ressignificaram o seu cotidiano. Os resultados apontam que ao descentralizar as ações, trazendo as crianças para uma construção coletiva das atividades propostas, o Projeto permitiu que as crianças se tornassem agentes culturais, no sentido de atuar ativamente nas interações com seus pares, na apropriação dos espaços e dos produtos que dele surgiram.

\section{CONCLUSÕES}

Nas experiências vivenciadas no projeto Brincar é o Melhor Remédio, discutimos possibilidades pedagógicas que reconheçam e valorizem a autoria e a autonomia de crianças em tratamento oncológico com os jogos e as brincadeiras ofertadas pelo Projeto. A entrada reativa, que pressupõe comportamentos menos expansivos e controladores dos adultos, as interações e mediações, que enfatizam relações pedagógicas menos verticalizadas, no sentido adulto-criança, oferecendo visibilidade ao protagonismo e as produções culturais dos infantis, foram possibilidades encontradas no contexto pesquisado. Nesse processo, destacamos a potencialidade da construção de brinquedos na promoção do protagonismo infantil, ao viabilizar meios para a materialização de ações criativas e autorais das crianças. As crianças projetaram as suas identidades nos brinquedos construídos, imprimindo as suas marcas em cada artefato produzido.

Além dos benefícios diretos às crianças, as atividades de pesquisas desenvolvidas no projeto Brincar é o Melhor Remédio têm contribuído para superar uma lacuna da área: o baixo número de produções acadêmicas que tratam das relações pedagógicas da Educação Física com crianças e adolescentes em tratamento oncológico. Por meio da Pesquisa-Ação Colaborativa, perspectiva teórico-metodológica empregada em nossas mediações pedagógicas, a produção de conhecimentos e a formação de professores têm se configurado como dimensões indissociáveis das atividades de extensão realizadas no projeto.

Por fim, ressaltamos que o olhar de pena, que enxerga a criança apenas pela sua enfermidade, é extremamente prejudicial para a autoestima de quem está 
no processo de enfrentamento da doença. Restituir a autonomia, a dignidade e a alegria da criança em tratamento oncológico é um desafio que se apresenta para as equipes multidisciplinares. Para alcançar esse objetivo, de uma coisa temos convicção: brincar é o melhor remédio.

\section{REFERÊNCIAS}

Azevêdo, A. V.S. O brincar da criança com câncer no hospital: análise da produção científica. Estudos de Psicologia, Campinas, v. 28, n. 4, out./dez. 2011.

Barbosa, R. F. M., Martins, R. L. R., \& Mello, A. S. Brincadeiras lúdico-agressivas: tensões e possibilidades no cotidiano na Educação Infantil. Movimento, Porto Alegre, v. 23, p. 159-170, jan./mar. 2017.

Bardin, L. Análise de conteúdo. Brasil: Edições 70 Brasil, 2011.

Brasil. Lei n. 8.069 de julho de 1990. Dispõe sobre o estatuto da criança e do adolescente. Diário Oficial da União, Brasília, 13 de jul. 1990.

Brougère, G. Brinquedo e cultura. 7. ed. São Paulo: Cortez, 2008.

Certeau, M. A invenção do cotidiano: artes de fazer. 8 ed. Petrópolis: Vozes, 1994.

Corsaro, W. Sociologia da infância. Porto Alegre: Artmed, 2011.

Finco, D., \& Oliveira, F. A sociologia da pequena infância e a diversidade de gênero e de raça nas instituições de educação infantil. In Faria, A. L. G., Finco, D. (Org.). Sociologia da infância no Brasil. Campinas: Autores Associados, 2011.

Gazeta, R. Desospitalização: atendimento domiciliar apresenta bons resultados. Diálogo Médico, v. 13, n. 4, p. 50 53, 1998.

Ibiapiana, I. M. L de M. Pesquisa colaborativa: investigação, formação e produção de conhecimentos. Brasília: Líber Livro Editora, 2008.

Instituto Nacional do Câncer. Disponível em: <http://www.inca.gov.br/wcm/dmdc/2017/cancer-infantojuvenil. asp>. Acesso em: 23 ago. 2018.

Instituto Nacional do Câncer. Disponível em: <https://www.inca.gov.br/noticias/sobrevida-pacientesinfantojuvenis-com-cancer-e-64-no-brasil>. Acesso em: 12 de maio de 2019.

Melo, C. K. (Re)criando o mundo no rodopio de um pião: a produção cultural do brinquedo em questão. Motrivivência, Florianópolis, Ano XVI, n. 22, p. 173-191, jun. 2004.

Mello, A. S., Silva, J. S., Jorge, R. S., Schneider, O., \& Santos, W. Representações sociais dos participantes de projeto esportivo de Vitória. Movimento, Porto Alegre, v. 24, n. 2, p. 399-412, abr./jun. de 2018.

Mello, A. S., Zandominegue, B. A. C., Barbosa, R. F. M., Martins, R. L. D. M., \& Santos, W. A Educação Infantil na Base Nacional Comum Curricular: pressupostos e interfaces com a Educação Física. Motrivivência, Florianópolis, v. 28, n. 48, p. 130-149, set. 2016

Mello, A. S., Zandominegue, B. A. C., Vieira, A. O., Silva, A. C., Assis, L. C., Barbosa, R. F. M., \& Martins, R. L. R. Pesquisas com crianças na educação infantil: diálogos interdisciplinares para produção de conhecimentos. Motrivivência (Florianópolis), v. 27, p. 1-16, set. 2016.

Mello, A. S., Santos, W., Rodrigues, L. A., \& Santos, R. S. O protagonismo de pessoas com deficiência intelectual no processo de ensino-aprendizagem da capoeira. Pensar a Prática (Online), v. 17, p. 214-227, jan./mar. 2014.

Mello, A. S., Ferreira Neto, A., \& Votre, S. J. Intervenção da educação física em projetos sociais: uma experiência de cidadania e esporte em Vila Velha/ES. Revista Brasileira de Ciências do Esporte, v. 31, p. 75-91, set. 2009.

Redin, M. M. Crianças e suas singularidades. In Muller, F., \& Carvalho, A. M. A. (Org.). Teoria e prática na pesquisa 
com crianças: diálogos com William Corsaro. São Paulo: Cortez, 2009.

Sarmento, M. J. A Sociologia da Infância e a sociedade contemporânea: desafios conceituais e praxeológicos. In Ens, R. T., \& Garanhani, M. C. Sociologia da Infância e a formação de professores. Curitiba: Editora Champagnat, 2013. Sarmento, M. J. Os ofícios da criança. In Instituto de Estudos da Criança da Universidade do Minho. (Org.). Os mundos sociais e culturais da infância. Braga, 2002, vol. II, p. 125-143.

Tardif, M. Saberes docentes e formação profissional. Petrópolis: Vozes, 2002.

Vieira, M. A., \& Lima, R. A. G. Crianças e adolescentes com doença crônica: convivendo com mudanças. In Cruz, S. H. V. (Org.). A criança fala: a escuta de crianças em pesquisa. São Paulo: Cortez, 2008. p. 375.

\section{AGRADECIMENTOS}

Agradecemos a toda comunidade da ACACCl, composta por gestores administrativos e pedagógicos, por profissionais de diferentes áreas do conhecimento, por voluntários e, sobretudo, crianças, adolescente e seus familiares pela parceria na construção coletiva do Projeto Brincar é o Melhor Remédio. 